THE KURUME MEDICAL JOURNAL

Vol. 34, P. 75-81, 1987

\title{
A Case of Neurilemoma of the Palate
}

\author{
TERUO HIEDA, TAMAKA OKINA, HIDETOSHI WAKAE*, SHIGERU HASHIMOTO*, \\ FUMIO GOTO*, TOMOKAZU MIYAMOTO* AND YUKIHIRO NAKASHIMA** \\ Departments of Oral Surgery and Anatomy**, Kurume University School of Medicine, \\ Kurume, 830 and *Department of Oral Surgery, Fukuoka Dental College, \\ Fukuoka, 814 Japan
}

Received for publication March 13, 1987

\begin{abstract}
Summary: A case of neurilemoma on the palatal region of a 44 year-old man was observed. The patient noticed a tumor on the right palatal region during treatment for dental caries, and came to our hospital for an examination. No particular change in facial findings was observed, and a small tumor (about $15 \times 12 \mathrm{~mm}$ ) covered with healthy mucosa was found in the right palatal region. The clinical diagnosis was pleomorphic adenoma, and the patient was operated on under general anesthesia. Histopathologically, the tumor tissue was full of hyperplastic nuclear spindle cells partially in a shelf arrangement. S-100 protein staining by the PAP method gave a positive reaction. With scanning and transmission electron microscopy the tumor tissue appeared fascicular and had a convoluted arrangement in each direction. These findings were suggestive of a Schwann cell origin for the tumor.
\end{abstract}

Key words: neurilemoma - benign tumor — neurologic - surgery - palate

\section{Introduction}

Neurilemoma, a tumor originating from the Schwann cell of the neurilemoma, has seldom been reported in the oral and maxillofacial region. A case of a neurilemoma in the right palatal region was recently observed.

\section{Case Report}

The patient was a 44 year-old man, who came to our hospital on Sept. 10, 1986, for the examination of a small tumor in the right palatal region. Neither the family history nor the past history revealed anything significant. History of present illness: The patient noticed a finger-sized tumor in the right palatal region during dental treatment at a dental clinic late August, 1986, and was referred to our hospital. Present status: general findings; moderate physique, good nutriture, no abnormal findings. Local findings; symmetrical, bean-sized bilateral submandibular lymphnodes, palpable without tenderness and mobile.

Intraoral findings: A $15 \times 12 \mathrm{~mm}$ hemispherical tumor was observed centering in the right palatal region. The tumor surface was covered with a healthy mucosa and was smooth. Palpation revealed a slightly hard elasticity without tenderness. The right maxillary molars were all vital teeth (Fig. 1).

$\mathrm{X}$-ray film findings: No bone absorption was observed in the palatal region. Clinical examination: unremarkable.

Clinical diagnosis: suspected pleomor- 
phic adenoma. Treatment and course: According to the above diagnosis, the tumor was excised under general anesthesia on Sept. 24, 1986. The mucosa was incised about $5 \mathrm{~mm}$ around the tumor and dullablated, and the tumor was resected en bloc. The bone surface showed no absorption and was smooth. The post operative course was eventless; no relapse had been observed by 4 months, postoperatively.

Findings in the resected tumor: The resected tumor was approximately $20 \times$ $10 \times 10 \mathrm{~mm}$, smooth on the surface, hard elastic in consistency (Fig. 2). The cut surface was citrine white and solid. The surface was covered with a thin capsula.

Histopathological findings: The tumor, which was present in the submucosal tissue, was clearly delineated from the normal tissue by thin fibrous connective tissue. The tumor tissue had a fascicular or convoluted arrangement. Each tumor cell had a spindle nucleus, and clusters of tumor cells were organized in a shelf arrangement. The so-called Verocay body was also observed, and there was also a portion with myxoma-like properties. PAP staining of the S-100 protein antibody fielded a strong positive reaction in the tumor cells (Fig. 3 and 4).

Electron microscopic findings: Under the scanning electron microscope, tumor cells had a fascicular and convoluted arrangement extending in each direction. With the transmission electron microscope, tumor cells had a regular arrangement and had the characteristics of Schwann cells. The nucleus was parallel to the long cellular axis, and rarely there were scattered nucleoli. Mitochondria, rough-surfaced endoplasmic reticulum, filaments, etc. were present in the cell body. Many of the tumor cells had complicated tanglements of the numerous processes and surrounding axial fibers. The outer circumferences of the tumor cells including processes were all covered with thin basement laminas (Fig. 5 and 6).
The above findings led to the diagnosis in the present case of a neurilemoma developing in the palatal region.

\section{Discussion}

In 1910 Verocay (Verocay, 1910) clarified that a neurilemoma was a lesion that was mainly due to an abnormal proliferation of Schwann cells, one of the nerve fiber elements. It has since been distinguished from a neurofibroma, and is generally called a neurinoma, neurilemoma, schwannoma, etc. Its tissue genesis has been described and recently, histopathological, electron microscopic and also immunohistochemical research demonstrated a S-100 protein, verifying that the neurilemoma is derived from Schwann cells (Moore, 1972).

Ishii and Kawabata (1968) reported that the tumor tissue was composed of three elements, the tumor cell, its process, and mixed existing vascular system. The morphology of the tumor cell was strongly suggestive of a Schwann cell origin. Their case was almost the same as our case. The disease can develop at any site where a nerve exists, and Enjoji et al. (1974) reported that the disease represented 825 of 8086 cases of benign soft tumors. The incidence is low however in the oral and maxillofacial region, and Bruce (1954) reported that only 2 of 130 cases of neurilemoma had developed in the oral and pharyngeal regions. In Japan, Momoi (1955) reported that 5 of 115 (4\%) operations or autopsy cases of neurilemoma had an onset in the oral region and Kajiyama et al. (1975), Kikuchi et al. (1979), and Shiromoto et al. (1983) reported an incidence of less than $1 \%$ in the oral maxillo facial region.

The tongue is the most common site for a neurilemoma in the oral maxillofacial region, followed by the buccal mucosa, mandible, oral floor, palate, gingiva and 
lips in that order. According to reports by various authors, the incidence in the palate is comparatively low (Gallo et al. 1977; Hamada et al. 1985; Hasegawa et al. 1984; Nakamura et al. 1985; Sato et al. 1986; Yamada et al. 1984; Yanagisawa et al. 1985).

The age of the patient at onset in most cases was in the teens, twenties and thirties in that order. There was no difference in age of onset between sexes (Yamashita et al. 1985; Kitamura et al. 1987).

The tumor, which is generally painless, show in growth, and up to approximately $2 \mathrm{~cm}$ in diameter, will appear in the submucosa as a tumor which is localized, spheroidal, and covered with a small hard elastic capsule. Due to the lack of symptoms, it is usually detected during dental treatment, and its clinical diagnosis as a pleomorphic adenoma may frequently lead to its surgical removal. Histopathological research usually leads to a diagnosis of a neurilemoma. Histopathologically, it can roughly be divided into Antonie A type (fascicular) and Antonie B type (reticular). The present case was classified as the former type because the nuclei of the tumor cells were eliptical and had a shelf arrangement.

In principle, surgical resection is the treatment of choice for a neurilemoma, and generally, the prognosis is eventless, but very rarely it takes a malignant course (Shirasuna et al. 1986). 4 months postoperatively, the patient in this case was taking a favorable course without abnormal findings.

(The results were presented at the 65 th Annual Session of the Fukuoka Dental College Society, Fukuoka, Jan. 30, 1987).

Acknowledgments : Greatful acknowledg. ments are expressed to Professors M. Murakami, T. Tomioka and C. Sujaku for their constant guidance and helpful advice.

\section{References}

BRUCE, K. W. (1954). Solitary neurofibroma (Neurilemoma, Schwannoma) of the oral cavity. OS OM OP. 7, 1150-1159.

Enjoji, M., Iwasaki, H. and Komatsu, K. (1974). Benign softtissue tumors in Japan - A statistic analysis of 8,086 tumors - Jap. J. Cancer Clin. 20, 594-609.

Gallo, W.G., Moss, M., Shapiro,D. N. and Gaul, J. V. (1977). Neurilemoma: review of the literature and report of five cases. J. Oral Surg. 35, 235-236.

Hamada, T, Shirakawa, M., Hasegawa, H., Kawai, T., Shimizu, N. and Ito, T. (1985). A case of schwannoma developed from the submandibular region. Jap. J. Oral Maxillofac. Surg. 31, 2457-2461.

Hasegawa, H., Shirakawa, M. and Kawai, T. (1984). A case of schwannoma developed from the floor of the mouth. Jap. J. Oral Maxillofac. Surg. 30, 1221-1225.

Ishi, H. and Kawabata, I. (1968). An electron microscopic study of neurilemoma. Pract. Otologica. 61, 231-237.

Kajiyama, M., Onizuka, K., NaKao, M. and TAteishi, T. (1975). A case of neurilemoma of the tongue. Japan. J. Oral Surg. 21, 328335.

Kikuchi, M., Miura, E. and Fujita, Y. (1979). Schwannoma of the tongue: Report of a case. Japan. J. Oral Surg. 25, 419-421.

Kitamura, A., Inokuchi, T. and Takahashi, $\mathrm{H}$. (1987). Neurilemoma at the hard palate: Report of a case. Jpn. J. Oral Maxillofac. Surg. 33, 428-431.

Mомог, I. (1955). A pathological study of neurinomas. Niigata Med. J. 69. 737-756.

Moore, B. W. (1972). Chemistry and biology of two proteins, S-100 and $14-3-2$, specific to the nervous system. Int. Rev. Neurobiol. 15, 215-225.

Nakamura, A., Saito, K., Yoshida, M., Michiwaki, Y., Suzuki, N., Michi, K. and Yamaguchi, A. (1985). A case of neurinoma of the sublingual area of the tongue. Jap. J. Oral Maxillofac. 31, 2218-2222.

Sato, Y., Noguchi, I., Ando, T., Takahashi, M., Hayama, S., Kurokawa, H., Usuki, S., Ide, F, Fuse, S., Kanda, H. and InABA, H. (1986). Neurinoma of the lower lip: Report of a case. Jpn. J. Oral Maxillofac. Surg. 32, 2140-2143. 
Shirasuna, K., Fukuda, Y., Kitamura, R., Ogawa, Y., IshidA, T., YAGi, T. and MiYazAKI, T. (1986). Malignant schwannoma of the mandible. Int. J. Oral Maxillofac. Surg. 15, 772-776.

Shiromoto, M., Shiromoto, K., Kimura, T., Takenaka, M., Kameyama, $T$. and Sujaku, C. (1983). A case of schwannoma of the mandibular body. Jap. J. Oral Maxillofac. Surg. 29, 547-552.

Verocay, J. (1910). Zur Kenntnis der "Neurofibrome". Beitr. z. Path. Anat. u. z. Allg. Path. 48, 1-69.

Yamada, K., Kamei, T., Shinoki, K. and Ohkubo,
T. (1984). Solitary neurofibroma of the tongue: Report of a case. Jpn. J. Oral Maxillofac. Surg. 30, 1549-1552.

Yamashita, N., Kameyama, T, Takenaka, M., Hieda, T., Tanaka, K., Tanaka, S., Nakamura, Y. and Sujaku, C. (1985). Schwannoma of the soft palate: Report of a case. Jpn. J. Oral Maxillofac. Surg. 31, 2467-2470.

Yanagisawa, S., Otake, H., Ono, T., Komori, A., Kanda, T. and Shimizu, M. (1985). Neurogenic tumors of the lip: Report of five cases. Jpn. J. Oral Maxillofac. Surg. 31. 325-330. 


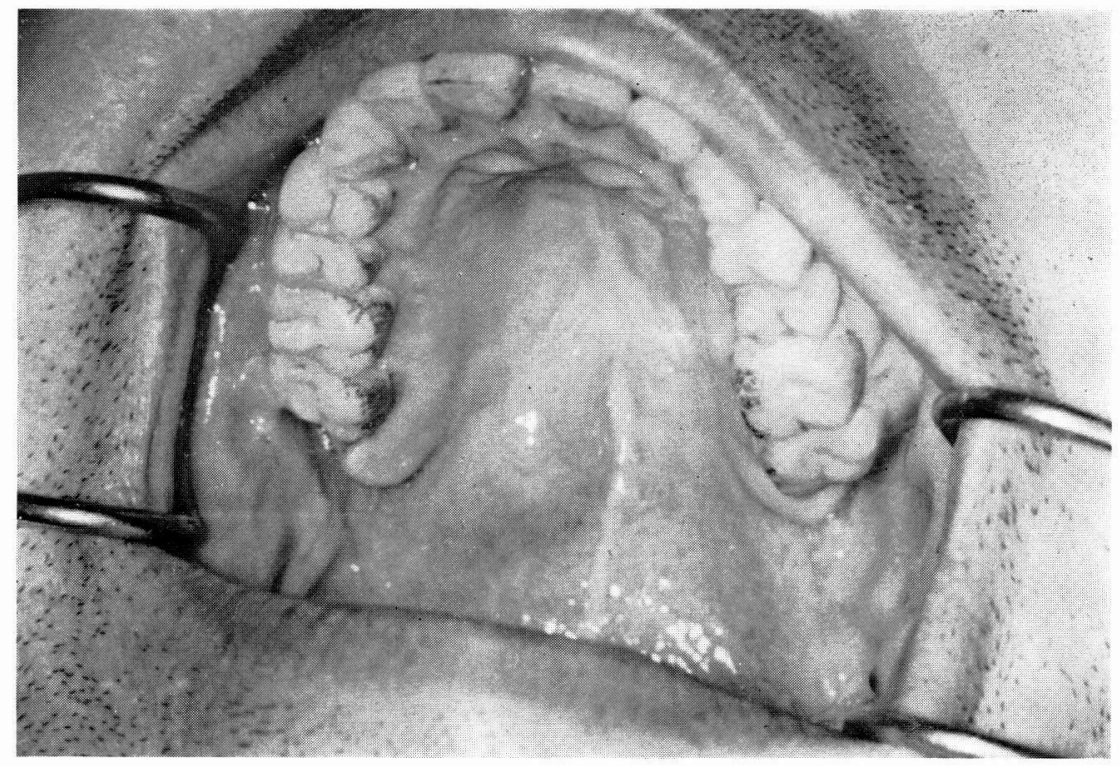

Fig. 1. Clinical appearance of the tumor before surgery

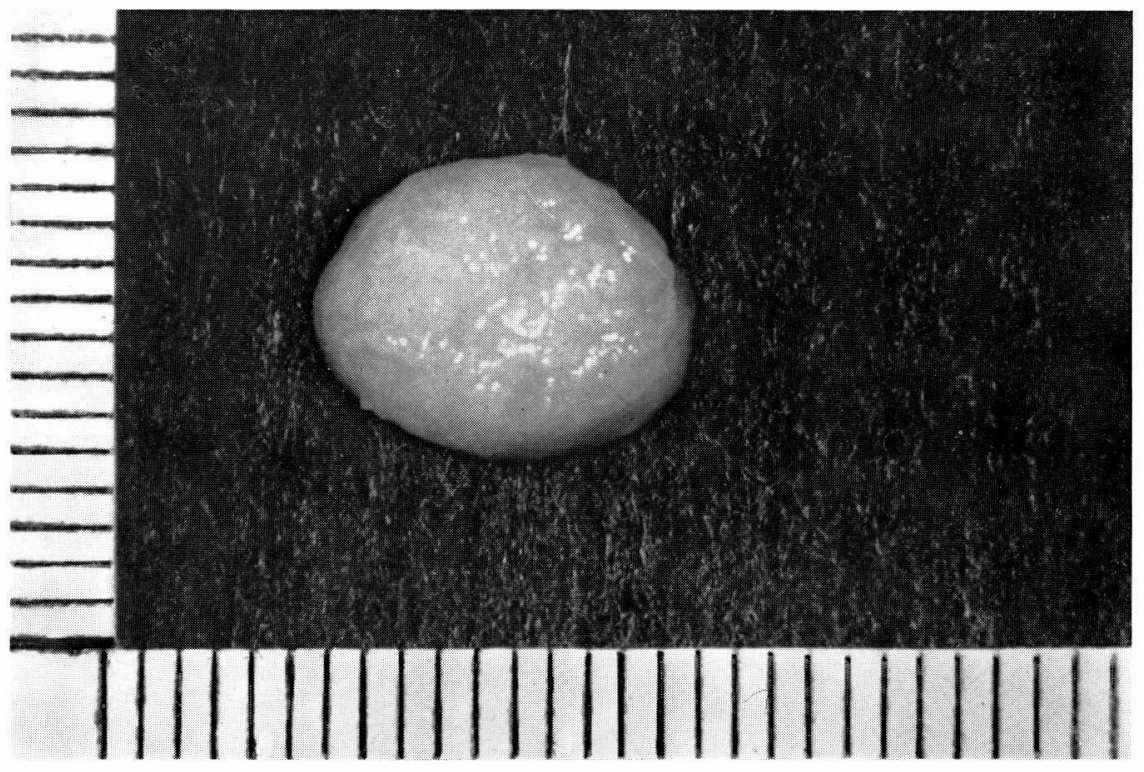

Fig. 2. Resected tumor 


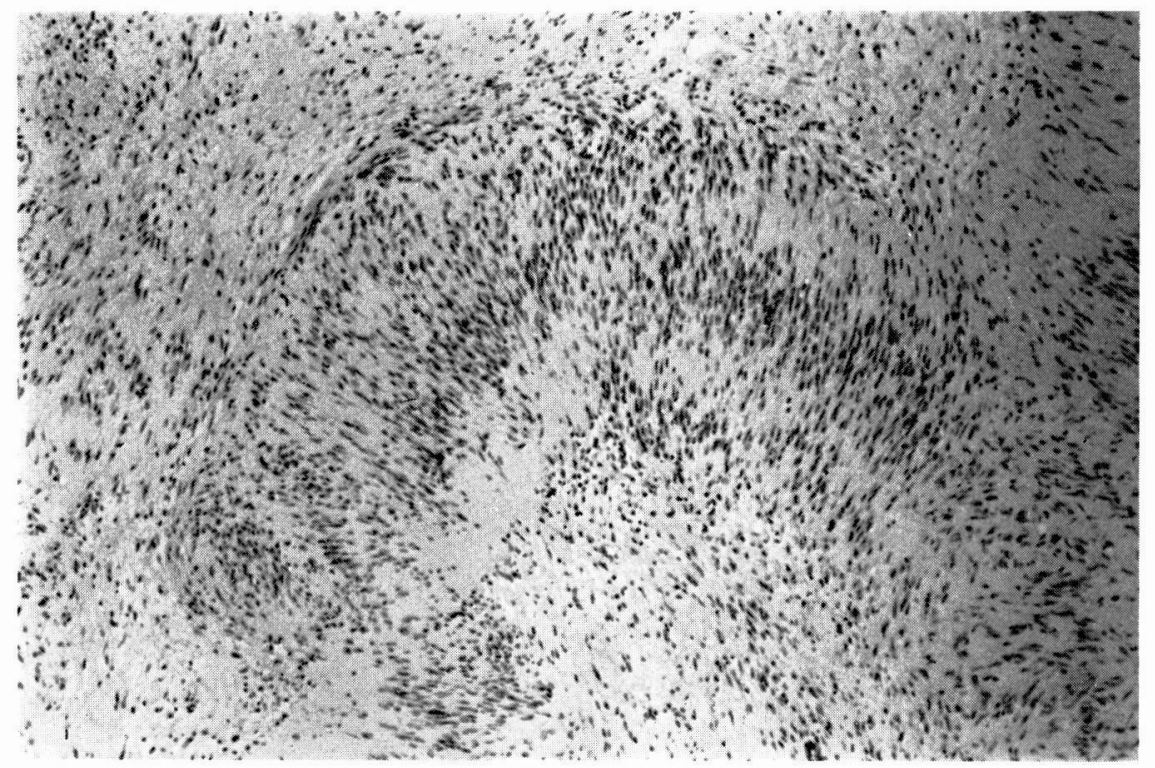

Fig. 3. Tumor tissue. H-E stain. $\times 20$

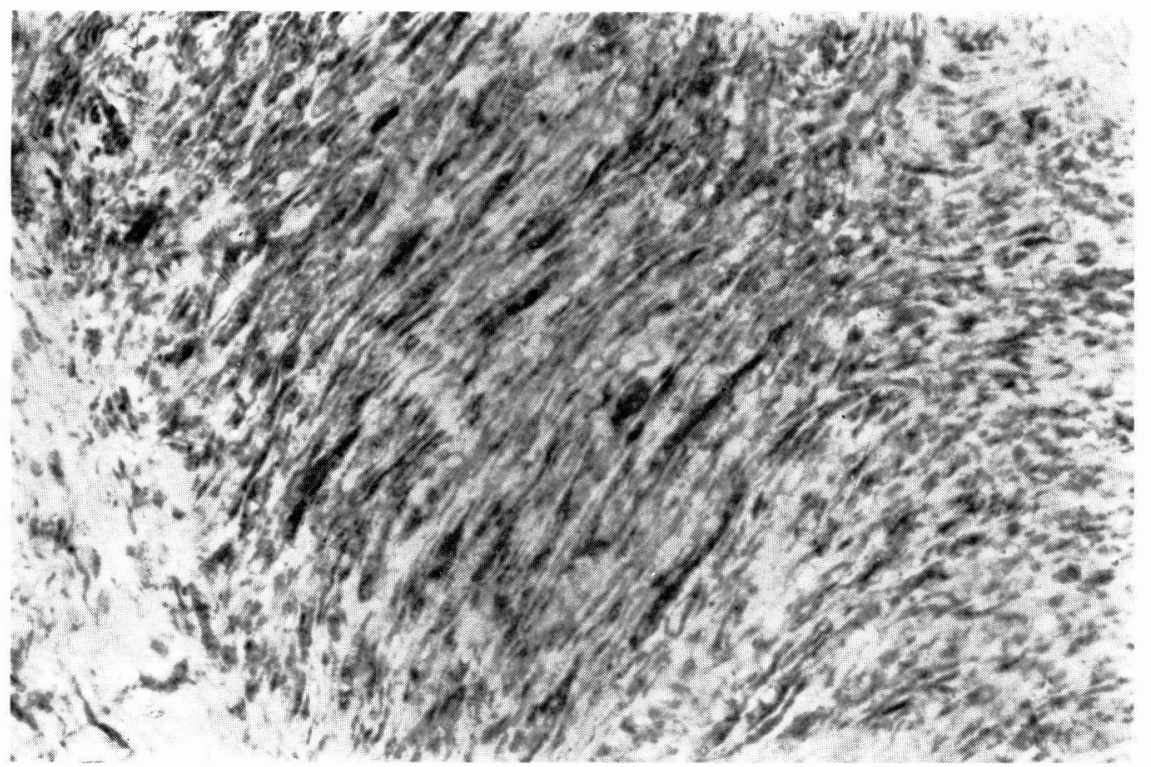

Fig. 4. PAP stain. $\times 100$ 


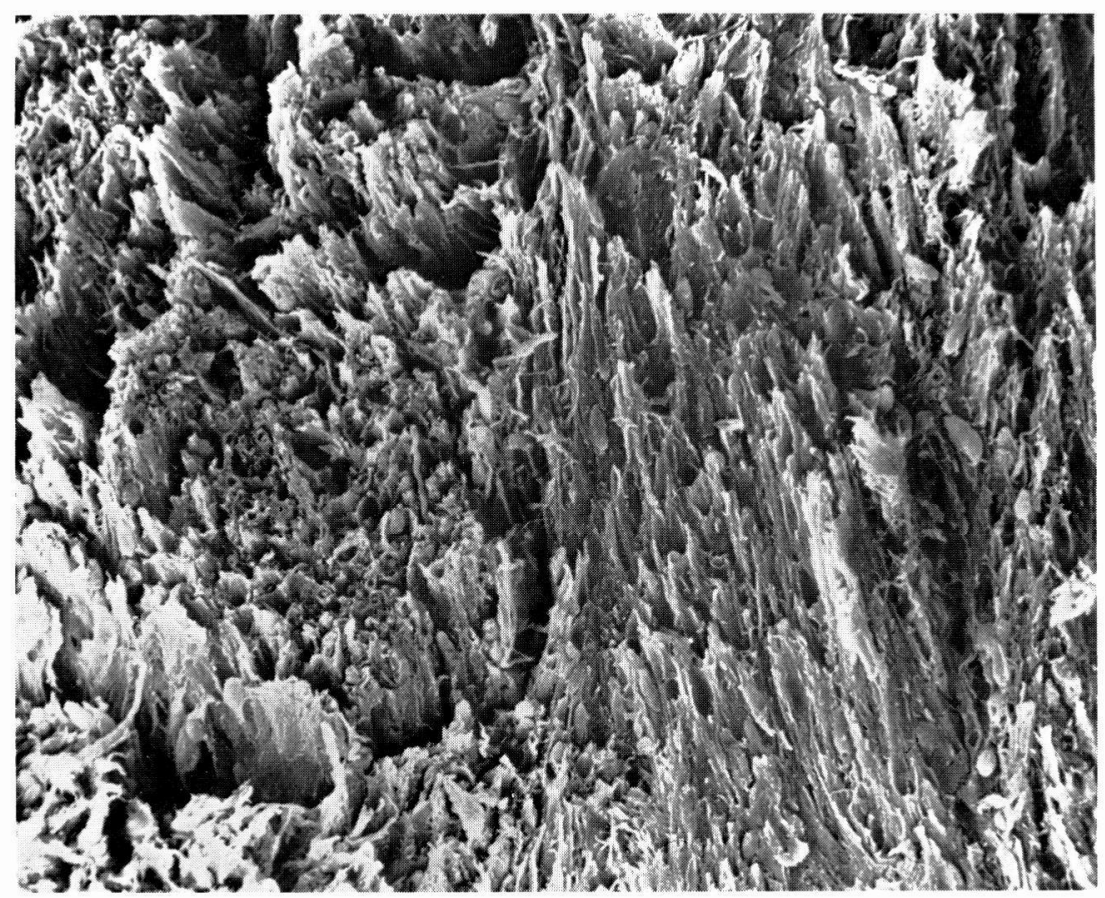

Fig. 5. Scanning electron micrography. $\times 500$

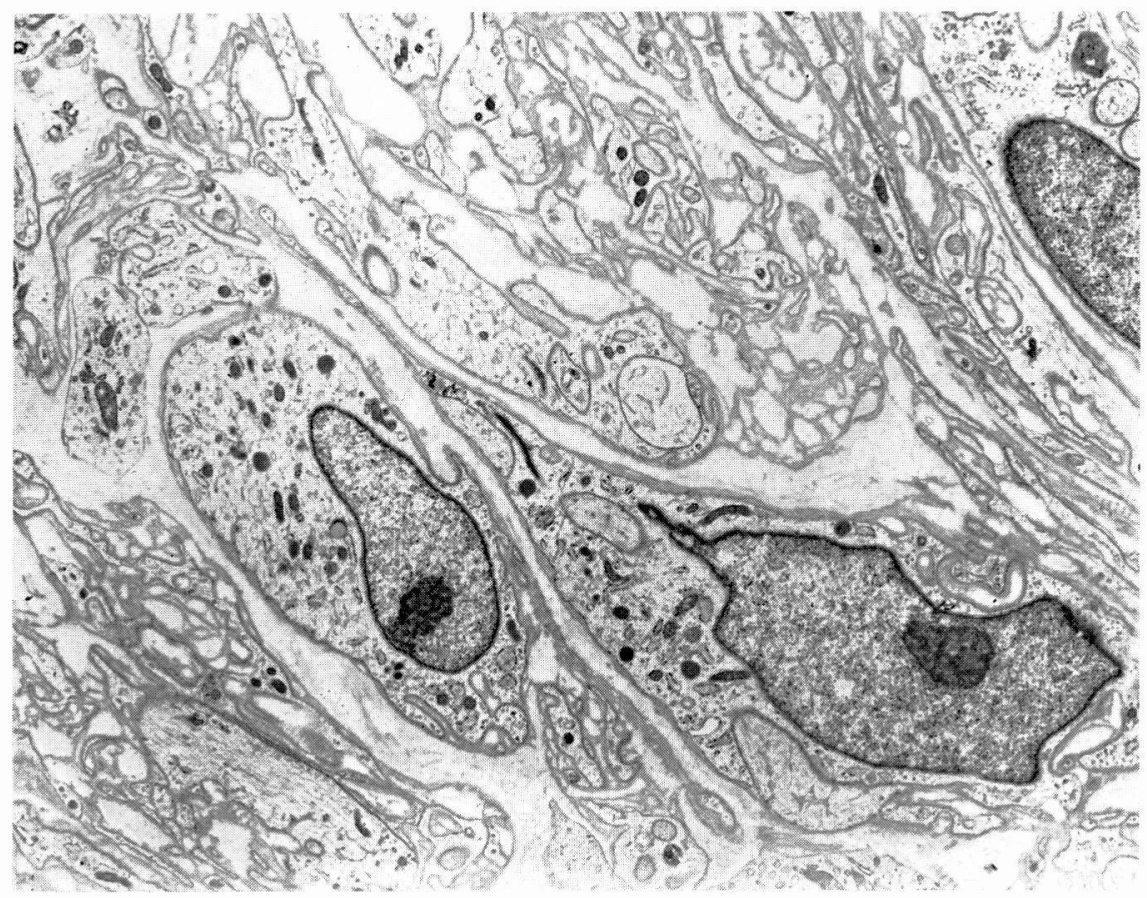

Fig. 6. Transmission electron micrography. $\times 6000$ 